\title{
Evaluation of a Longitudinal Institutional Advanced Pharmacy Practice Model
}

Erin Christensen, ${ }^{a}$ PharmD, BCPS, Emory University Hospital Midtown, Atlanta, Georgia

Kara Webber, ${ }^{a}$ PharmD, MHA, United Hospital, St Paul, Minnesota

Janet L. Kelly, PharmD, University of Washington Medical Center, Seattle, Washington

Stanley S. Weber, BS Pharm, PharmD, BCPP, University of Washington School of Pharmacy, Seattle, Washington

Teresa A. O'Sullivan, BSPharm, PharmD, BCPS, University of Washington School of Pharmacy, Seattle, Washington

${ }^{a}$ At the time of this project Drs. Christensen and Webber were pharmacy residents at UW Medicine, Seattle, Washington

\begin{abstract}
Objective: To evaluate a longitudinal experiential training model for advanced pharmacy practice experiences (APPES).

Innovation: A six-month longitudinal pilot program named the Focused Institutional Longitudinal Experience (FILE) program was developed at two academic medical centers to maximize active participation of the student and minimize the time spent orienting and onboarding students to each APPE experience. A unique component of the FILE program is the longitudinal service project, which involved a medication use evaluation, including a review of published literature and drug policy recommendations to medical center quality committees. Analysis: Student ratings regarding the quality and value of the FILE student experience was compared to the traditional APPE model. Nine quality measures were compared (e.g. amount of opportunity for direct patient care experience, learning, integration into healthcare team, and accountability for patient outcomes) between students from the FILE program to peers completing similar APPEs outside the FILE program. FILE students and APPE preceptors also completed surveys regarding the value of several program aspects. Key Findings: There was no difference between FILE and non-FILE student self-rated measures of APPE quality, and thus the decision to participate in a longitudinal APPE program should be based on the personal preference of the student. Students in the FILE program agreed or strongly agreed (mean score 4.3) that they felt prepared for post-graduate training at the completion of the program. The potential value that students in a longitudinal program might bring to the site is reinforced by the general agreement by preceptors in the end of year survey that FILE students take less of their time to orient to their service and the trend toward perception that FILE students are more likely to independently participate in patient care activities. Next Steps: To address feedback on preceptor-mentor role and the desire for more interaction with pharmacy residents, students are now paired with a pharmacy resident, and the student and resident work together on the service project with a clinical pharmacist as an advisor. Updated standards of practice clearly delineate the roles and responsibilities of students, residents, and the clinical pharmacist preceptor. Annual surveys of FILE students and preceptors provide necessary feedback to continuously improve the quality of the program.
\end{abstract}

Keywords: quality improvement, advanced pharmacy practice experience, longitudinal pharmacy practice experience, health-system pharmacy

\section{Description of the Problem}

Health-system pharmacists are increasingly expected to expand patient care services. In 2010, the American Society of Health-System Pharmacists (ASHP) held the Pharmacy Practice Model Initiative, a summit designed to identify trends in health-system pharmacist responsibilities. Several of the recommendations have directly resulted in an increased workload for pharmacists in health-system practice. ${ }^{1}$ The authors of the summit consensus document also accurately predicted that health systems would be under increasing pressure to cut operating costs, pharmacy department operations would need to become more efficient, and financial

Corresponding Author: Janet L. Kelly, PharmD

University of Washington Medical Center

Department of Pharmacy Services

Box 356015, 1959 NE Pacific St, Seattle, Washington, 98195

Email: rxpress@uw.edu pressures would force health systems to pursue significant changes in how their pharmacy resources are used. These realities have meant that the increase in pharmacist workload has not been offset by an increase in staffing. In addition to increasing direct patient care responsibilities, health-system pharmacists have also been asked to increase their clinical teaching responsibility. Standards issued by the Accreditation Council for Pharmacy Education (ACPE) require several core experiences in the health-system setting. ${ }^{2}$ Concurrently, the number of students graduating from US pharmacy schools nearly doubled between 2005 and 2014. ${ }^{3}$ These dual circumstances have placed unprecedented performance demands on the health-system pharmacist.

To meet these challenges, some health systems have partnered with pharmacy schools to develop new experiential training models that allow student pharmacists to complete multiple required APPEs within one health system. ${ }^{4,5}$ This approach helps schools to increase the number of APPE sites 
available to students, and hospitals have been able to expand clinical pharmacy services without increasing costs. Challenges identified include lack of space, difficulty securing continuous computer access for students, and coordinating scheduling with multiple pharmacy schools. However, the conclusions in these reports are largely based on author impressions, rather than collected data. A gap exists in the health-systems pharmacy literature regarding quality indicators that can be used to assess the success of longitudinal programs and identify areas needing improvement.

\section{Statement of the Innovation}

In academic year 2015-2016, the UW Medicine Health System pharmacy department, which includes University of Washington and Harborview Medical Centers, and University of Washington School of Pharmacy collaborated to develop and implement a longitudinal APPE pilot program, named the Focused Institutional Longitudinal Experience (FILE). Students participating in the FILE program completed six of their nine APPEs in a sequential manner. The six APPEs were split as evenly as possible between the academic medical centers to provide students with a wider variety of APPEs compared to those available at one institution. The medical centers share an electronic medical record system, providing ease of student onboarding and transition between institutions. Students completed four APPEs in the acute care setting (i.e. general medicine, cardiology, and two electives), one clinic, and one pharmacy administration APPE. Limiting the program length to six, four-week APPEs allowed FILE students to complete some of their APPEs in other practice settings. Both medical centers have a long history of hosting APPE students for individual four-week rotations.

One unique component of the FILE program is the longitudinal service project, which involved a medication use evaluation, including a review of published literature and recommendations for our Pharmacy and Therapeutics Committee or other medical center quality committees. The students presented their project in a poster format at a local or regional pharmacy conference and prepared a written manuscript in a format appropriate for journal publication. FILE students were also paired with a longitudinal preceptormentor, with whom they met a minimum of three times during the course of the program (i.e. beginning, middle, and end of the six-month program). The longitudinal preceptor-mentor provided general career guidance (review and feedback on curriculum vitae, job/residency applications, and interview tips) as well as guidance with the service project.

In addition, we implemented group education sessions to enhance efficiency for preceptors. All students on rotation at each site met with a single preceptor each week to discuss a specific disease state, therapeutic topics, and/or patient cases. The group teaching sessions were not limited to FILE students, but included all APPE students at the site each month.
To participate in the FILE program, students submitted an application (i.e. curriculum vitae and letter of intent) and completed an informational interview with preceptors from the medical centers and faculty from the school of pharmacy. Applicants were provided constructive feedback on their letter and curriculum vitae following the interview process. Students choosing to participate in the FILE program submitted elective inpatient and ambulatory clinic APPE preferences. A study of the pilot cohort was conducted to answer three questions: 1) Were perceived quality measures different for students completing the FILE program versus non-FILE peers? 2) What value did the FILE students attribute to the various components of the program? 3) Did APPE preceptors discern any benefit to their workload from a longitudinal student versus a traditionally-placed student?

\section{Critical Analysis}

In order to facilitate comparison of learning outcomes between FILE and traditionally-placed students, a cohort of control (non-FILE) students was identified from students in the same graduating class. Inclusion criteria for control students were: completion of six sequential or nearly-sequential APPEs in inpatient and clinic settings and starting or ending the six APPEs in the same month as one of the FILE students. Control students thus had an APPE schedule as similar as possible to the FILE students', but completed their APPEs in a variety of healthcare systems, rather than just one healthcare system. De-identified demographic and student self-rated learning outcomes data were obtained from the student services and experiential education databases through a data broker who did not participate in data analysis. The study protocol qualified for exemption after review by the University of Washington Human Subjects Division subcommittee.

At the end of each APPE, all students were required to assess the quality of their learning experience by ranking nine statements (see Table 1). Student self-scored general learning questions were compared using a Welch's t-test for unequal variances. Student self-scored role on the interprofessional team and accountability for patient outcomes were compared with a chi-squared 4-sample test of equality to determine overall differences between FILE students and their non-FILE comparators. All statistical tests were completed using R, version 3.3.1 (The R Project, Vienna, Austria). In addition, students were surveyed at the end of the program on perceived value of the program. Preceptors were surveyed at the end of the academic year on the perceived workload benefits of the program.

Of 96 students in the 2016 graduating class, 16 students in the FILE program and 19 control students were included in the final analysis. One-third of control students' APPEs were completed at the same healthcare system as the FILE students' APPEs, while two-thirds were completed at other healthcare systems. Table 1 details the student self-rated APPE quality 
measures for FILE vs. control students. Students in the FILE program had quality measure scores similar to those of controls, suggesting similar educational outcomes, and thus the decision to participate in a longitudinal program should be based on personal preference of the student. The one significantly different quality measure, accountability for patient outcomes, may have been due to enhanced student familiarity with the site, and thus more active participation. However, previous work has shown that all students at these academic medical centers report being more fully integrated into the medical team and be fully accountable to the healthcare team for patient outcomes than are students in other clinical sites. ${ }^{7}$ To evaluate this hypothesis, a comparison between control students while at the academic medical centers (about one-third of their APPEs), versus other practice sites (two-thirds of APPEs) was conducted. The proportions of students reporting being fully integrated into the healthcare team and fully accountable for patient outcomes was significantly higher in APPEs completed at the academic medical centers compared to APPEs at other practice sites ( $p=0.0001$ for both measures).

Fifteen of the 16 FILE students who completed the program responded to an optional survey at the conclusion of the program and 16 of 48 APPE preceptors responded to an optional survey at the conclusion of the academic year (Table 2). Student and preceptor survey scores, coupled with the generally higher scores on student-perceived quality measures, indicate that the program was relatively successful. The general agreement by preceptors that FILE students take less of their time to orient to their service and the trend toward perception that FILE students are more likely to independently participate in patient care activities reinforces the potential value that students in a longitudinal program might bring to the site. One area of improvement identified from the student surveys is the desire for enhanced mentorship and guidance with the service project. Comments from the preceptor surveys identified duplication of efforts (e.g. presence of multiple pharmacy representatives on multidisciplinary rounds and gathering and interpreting patient data) between the students and pharmacist/resident preceptor, and the need for more clearly-defined roles and responsibilities for all pharmacy staff.

An intriguing result is the suggestion arising from the preceptor survey that FILE students might facilitate expansion of patient care services and allow pharmacist involvement in other non-direct patient care activities, such as hospital committees and research activities. Although pharmacy students should not be brought on site to replace pharmacy personnel, ACPE Standards 2016 mandate student participation in direct patient care activities and thus require that students augment existing patient care services at a site. ${ }^{2}$ The limiting factor is the student's competency and efficiency in performing patient care activities. Evidence suggests that highly competent students will make more patient care interventions, ${ }^{8}$ which might help preceptors with their workloads. The key lies in getting students to the stage where they become highly competent, without further burdening their preceptors. The longitudinal model is one tool that may increase the proportion of health-system partners that currently view students as pharmacist extenders and thus indispensable. ${ }^{9,10}$

This evaluative project encountered some limitations. The return rate on the preceptor surveys was lower than desired. Poor preceptor recall of student performance early in the academic year and uncertainty regarding students in the FILE program may have contributed to the low response rate. Additionally, the surveys were sent to both acute care and ambulatory care preceptors. FILE students completed only one ambulatory clinic rotation, which necessitated learning a new computer system and completing an additional orientation. Therefore, no difference was seen or expected between FILE students and their non-FILE student counterparts in this setting.

\section{Next steps}

The FILE program has continued as an APPE option for students. To address the feedback regarding the utility of the longitudinal preceptor-mentor and the desire for more interaction with pharmacy residents, students in the subsequent academic year were assigned to a pharmacy resident who acted as the longitudinal preceptor and mentor for the year. The resident and the student worked collaboratively on the pharmacy service project, with guidance from a clinical pharmacist with specific content knowledge relevant to the project. To address preceptor uncertainty about the role and responsibility of students and residents on rotation, updated standards of practice were implemented which clearly delineated the roles and responsibilities of all pharmacy staff involved in direct patient care activities. The duration of the FILE program continues to be six months due to the majority of the students reporting that this was an appropriate length of time. Surveying FILE students in this next academic year will enable feedback on the changes made to improve quality of the student experience. Future studies should explore training methods that most effectively prepare students to assist preceptors in providing optimal care for patients.

Acknowledgements: None

Funding/Support: None

Other Disclosures: None 


\section{References}

1. The consensus of the Pharmacy Practice Model Summit. Am J Health-Syst Pharm 2011;68(12):1148-52. doi: 10.2146/ajhp110060

2. Accreditation Council for Pharmacy Education. Accreditation Standards and Key Elements for the Professional Program in Pharmacy Leading to the Doctor of Pharmacy Degree ("Standards 2016"). Published February 2015. Available at: https://www.acpeaccredit.org/pdf/Standards2016FINAL.pdf. Accessed August 15, 2018.

3. Grabenstein JD. Trends in the numbers of US colleges of pharmacy and their graduates, 1900-2014. Am J Pharm Educ 2016;80(2): Article 25. doi: 10.5688/ajpe80225

4. Hatton RC, Weitzel KW. Complete-block scheduling for advanced pharmacy practice experiences. Am J HealthSyst Pharm 2013;70(23):2144-2151. doi: 10.2146/ajhp130148

5. Taylor RA, Wisneski SS, Kaun MA, Parteleno P, Williams J, Goldman MP. Sequential advanced pharmacy practice experiences at one institution for students from three pharmacy schools. Am J Health-Syst Pharm.

2013;71(2):140-144. doi: 10.2146/ajhp130139
6. Frasiolas JA, Wright K, Dzierba AL. Evaluation of a longitudinal advanced pharmacy practice experience. $A m$ J Pharm Educ 2017;81(3): Article 52. doi: 10.5688/ajpe81352

7. O'Sullivan TA, Lau C, Sy E, Moogk H, Weber SS, Danielson J. Analysis of the student experience in an attending pharmacist model general medicine advanced pharmacy practice experience. Am J Pharm Educ. 2017;81(4): Article 66. doi: 10.5688/ajpe81466

8. Lounsberry JL, Pereira CR, Harris IM, Moon JY, Westberg SM, Kolar C. Tracking patient encounters and clinical skills to determine competency in ambulatory care advanced pharmacy practice experiences. Am J Pharm Educ 2016;80(1): Article 14. doi: 10.5688/ajpe80114

9. Ashby DM. Permission granted. Am J Health-Syst Pharm 2011;68(16):1497-1504. doi: 10.2146/ajhp110260

10. Smith KM, Phelps PK, Mazur JE, May JR. Relationships between colleges of pharmacy and academic medical centers. Am J Health-Syst Pharm 2008;65(18):17501754. Doi: 10.2146/ajhp080145 
Table 1. Student Self-Rated APPE Quality Measures for FILE students ( $\mathrm{N}=16)$ and Non-FILE Control Students ( $\mathrm{N}=19$ )

\begin{tabular}{|c|c|c|c|}
\hline Measure & $\begin{array}{l}\text { FILE Student APPEs } \\
\qquad \begin{array}{l}\mathrm{N}=96 \\
\mathrm{M}(\mathrm{SD})\end{array}\end{array}$ & $\begin{array}{l}\text { Non-FILE Student } \\
\text { APPEs N=114 } \\
\text { M (SD) }\end{array}$ & $p$ value $^{a}$ \\
\hline $\begin{array}{l}\text { Amount of effort put into experience compared to other } \\
\text { APPEs, mean score }\end{array}$ & $3.58(0.90)$ & $3.68(0.80)$ & 0.36 \\
\hline $\begin{array}{l}\text { Amount of learning achieved compared to other APPEs, mean } \\
\text { score } \mathrm{b}^{\mathrm{b}}\end{array}$ & $3.91(0.80)$ & $4.07(0.86)$ & 0.15 \\
\hline $\begin{array}{l}\text { Sufficient number of patients or activities to improve your } \\
\text { ability to practice pharmacy, mean score }{ }^{c}\end{array}$ & $4.72(0.52)$ & $4.60(0.65)$ & 0.11 \\
\hline $\begin{array}{l}\text { Sufficient opportunities to interact with other healthcare } \\
\text { professionals to improve ability to practice pharmacy, mean } \\
\text { score }^{c}\end{array}$ & $4.69(0.74)$ & $4.58(0.75)$ & 0.26 \\
\hline $\begin{array}{l}\text { Sufficient resources to improve ability to practice pharmacy, } \\
\text { mean score }{ }^{c}\end{array}$ & $4.61(0.61)$ & $4.62(0.62)$ & 0.99 \\
\hline $\begin{array}{l}\text { Presence of an environment that respects and encourages } \\
\text { learning, mean score }{ }^{c}\end{array}$ & $4.69(0.62)$ & $4.59(0.78)$ & 0.24 \\
\hline \multirow{2}{*}{$\begin{array}{l}\text { Opportunity for meaningful interactions with other healthcare } \\
\text { professionals, mean score }^{c}\end{array}$} & $4.47(0.80)$ & $4.23(0.94)$ & 0.05 \\
\hline & \# Respondents (\%) & \# Respondents (\%) & \\
\hline Role on the interprofessional team & & & 0.08 \\
\hline Full integration & $46(48)$ & $34(30)$ & \\
\hline Active participation & $43(45)$ & $70(61)$ & \\
\hline Passive listening & $4(4)$ & $7(6)$ & \\
\hline Insufficient opportunity & $3(3)$ & $3(3)$ & \\
\hline Accountability for patient outcomes ${ }^{d}$ & & & 0.0006 \\
\hline Full accountability & $58(60)$ & $45(40)$ & \\
\hline Partial accountability & $27(28)$ & $62(55)$ & \\
\hline No accountability & $2(2)$ & $3(3)$ & \\
\hline Insufficient opportunity & $9(9)$ & $3(3)$ & \\
\hline
\end{tabular}

${ }^{a}$ Mean (M) values compared using a Welch's t-test for unequal variances and categorical variables compared using a 4-sample chisquared test

${ }^{\text {b}}$ Response options: 1 (much less than), 2 (less than), 3 (about the same as), 4 (more than), and5 (much more than)

'Response options: 1 (highly disagree), 2 (disagree), 3 (neither agree nor disagree), 4 (agree), and5 (highly agree)

${ }^{\mathrm{d} O n e}$ response was blank, resulting in 113 usable responses

FILE=focused institutional longitudinal experience; APPEs=advanced pharmacy practice experiences; M=Mean; SD=standard deviation 
Table 2. Responses to FILE Student Survey $(\mathrm{N}=15)$ and Preceptor Survey $(\mathrm{N}=16)$

\begin{tabular}{lc}
\multicolumn{1}{c}{ Survey Item } & Mean Response Score ${ }^{\mathrm{a}}$ \\
\hline Student survey responses & 4.3 \\
I feel prepared for residency or post graduate training & 3.7 \\
The service project was a valuable experience & 4.1 \\
The poster presentation of service project was a valuable experience & 2.5 \\
The primary preceptor-mentor was a valuable resource & 3.9 \\
The group teaching sessions were valuable & \\
$\begin{array}{l}\text { Preceptor survey responses } \\
\text { FILE students required less preceptor time to orient to service than non-FILE students }\end{array}$ & 3.9 \\
FILE students more actively participated in direct patient care activities than non-FILE & 3.6 \\
students & 3.5 \\
FILE students were more independent than non-FILE students & 2.8 \\
Preceptors were able to provide more direct patient care and work on additional & \\
projects when precepting a FILE than a non-FILE student &
\end{tabular}

aResponse options: 1 (highly disagree), 2 (disagree), 3 (neither agree nor disagree), 4 (agree), and 5 (highly agree)

FILE=Focused Institutional Longitudinal Experience 